\title{
Guayangareo: la «Nueva Michoacán» contra el obispo Vasco de Quiroga y la búsqueda de una integración social en el siglo XVI
}

\section{Guayangareo. The «New Michoacan» versus the Bishop Vasco de Quiroga and the Search for an Integration in the XVI Century}

\section{Fernando Méndez Sánchez ${ }^{1}$}

Universidad Popular Autónoma del Estado de Puebla MÉXICO

fms291077@gmail.com

\section{Mariana Durán Márquez²}

Universidad Panamericana, campus México

MÉXICO

mduranm@up.edu.mx

[Hipogrifo, (issn: 2328-1308), 5.2, 2017, pp. 415-428]

Recibido: 16-01-2017 / Aceptado: 25-04-2017

DOI: http://dx.doi.org/10.13035/H.2017.05.02.24

Resumen. En los inicios de la Nueva España, particularmente a mediados del siglo XVI, el obispo Vasco de Quiroga mantuvo un serio enfrentamiento con los habitantes de Guayangareo, quienes buscaban obtener el nombre de Michoacán,

1. Catedrático de la Facultad de Derecho de la Universidad Popular Autónoma del Estado de Puebla, Catedrático del Posgrado de Derecho y Ciencias Políticas de la Universidad Popular Autónoma del Estado de Puebla. Candidato a Doctor en Derecho, por la Benemérita Universidad Autónoma de Puebla.

2. Profesora investigadora y Secretaria Académica del Posgrado en Derecho, ambas en la Facultad de Derecho de la Universidad Panamericana campus México. 
que originalmente correspondía al obispado establecido por Quiroga con base en diversas Cédulas Reales. El conflicto, convertido en un juicio que duraría varios años, mostraría el interés de Vasco de Quiroga, por una integración social entre naturales y europeos de la Nueva España.

Palabras clave. Vasco de Quiroga; Michoacán; Guayangareo; Nueva España; indígenas.

Abstract. In the beginnings of New Spain, particularly in the middle of the sixteenth century, Bishop Vasco de Quiroga maintained a serious confrontation with the inhabitants of Guayangareo, who sought to obtain the name of Michoacán, which originally corresponded to the bishopric established by Quiroga based on Various Royal Cedars. The conflict, turned into a trial that would last several years, would show the interest of Vasco de Quiroga, for a social integration, between the naturals and the Europeans of New Spain.

Keywords. Vasco de Quiroga; Michoacán; Guayangareo; New Spain; Indigenous.

\section{INTRODUCCIÓN}

Nacido en 1490, en la provincia de Ávila en Castilla-León, en la actual España; Vasco de Quiroga, ha pasado a la historia por su intensa labor humanitaria, basada en principios católicos, que desarrolló, al punto de ser un verdadero antecedente de los Derechos Humanos en el nuevo continente.

Experto en derecho canónico, gracias a sus estudios en la célebre Universidad de Salamanca que realizó durante la segunda década del siglo XVI; arribó a la Nueva España en 1530; ; sólo nueve años después de la caída de la Ciudad de Tenochtitlán, formando parte de la Segunda Audiencia. Para 1532, es asignado a la actual región de Michoacán, con la misión de buscar pacificar a los todavía belicosos naturales de la zona, siendo elegido como primer obispo de la Diócesis en 1536. Sin embargo, su atención hacia los naturales, así como una calidad humana poco valorada por muchos de los peninsulares que se asentaron en la región, provocó diversos roces con los peninsulares, dando lugar a un rompimiento de los feligreses europeos con el obispo.

Cuando Vasco de Quiroga se enfrentó contra los vecinos de Guayangareo, el asunto versaba sobre el asentamiento de éstos y el deseo de nombrar al nuevo asentamiento Michoacán4.

Varios vecinos españoles, al parecer habían decidido dejar Michoacán y asentarse en Valle de Guayangareo que se ubicaba aproximadamente a ocho leguas de la Ciudad de Michoacán, un lugar inhabitado y azotado por fuertes vientos acorde a lo descrito por el mismo Quiroga:

3. Calllens Paul, 1959, p. 27.

4. Vasco de Quiroga contra los Vecinos de Guayangareo, Justicia 173, N.1 R2, R12, México, 1567, fojas. 1-3, AGI. 
sin razón y sin causa legítima alguna, desampararon la dicha ciudad y iglesia catedral, su parroquia, donde estaba quietos y sin necesidad de las que ahora dicen que tiene en el sitio de Guayangareo, donde se pusieron que es un yermo siete u ocho leguas de la dicha ciudad, en un valle acanalado norte sur que les lleva las cubiertas de las casas y los trae medio sordos el gran viento que allí reina; en que hay mosquitos y se les ha quemado por dos o trece veces, o más que parece misterio, siete u ocho casas pajizas que han hecho allí [...] parece un cortijo y lo llama la ciudad de Michoacán, y ahora, después que ha visto los inconvenientes y defectos que el sitio tiene, dicen y confiesan claramente que no puede allí sustentarse, [...] perpetuarse, sino se les da en efecto casi toda la provincia de Michoacán de indios por esclava, para que allí los sirvan y ayuden de quince leguas alrededor del sitio, que puede ser hasta quince o veinte vecinos los que allí residen y les hagan las casas y les traigan caños de agua imposibles de traerse, y más imposible de sustentarse, y después de todo esto de muy poco provecho o ningu[n], oye más de esto los tributos de cinco o seis cabeceras de pueblos ${ }^{5}$.

Tal como se aprecia, los vecinos españoles habían abandonado la original Ciudad y se habían establecido en la actual región de Morelia, donde solicitaban indígenas para que prácticamente en calidad de esclavos, les construyeran casas y trajeran agua. Ante tales demandas, el obispo de Michoacán suplicaba al Consejo, que forzara a tales vecinos a regresar a las cercanías de la Catedral o bien a establecerse en otro barrio más cercano, en donde el acceso a beneficios de higiene y seguridad fueran más fáciles de brindar y menos onerosos.

De igual manera, Vasco de Quiroga, señala que el llevar a indígenas tan lejos de sus hogares sería sumamente perjudicial para los primeros, y que el uso del nombre de Michoacán para el paraje, era usurpación del mismo, dado que el reconocimiento de dicho nombre yacía con la Catedral y la Ciudad originaria, acorde a las Mercedes Reales. También resultaría sumamente oneroso para un Obispado con necesidades económicas urgentes, ya que los vecinos solicitaban a su vez de iglesia y clérigos que impartieron los sacramentos, cuando en la Ciudad originaria contaban con ellos de manera por demás cumplida ${ }^{6}$.

\section{EL ORIGEN JURÍDICO DE MICHOACÁN}

Indudablemente uno de los puntos que más preocupaba al obispo de Michoacán, era el referente a que la Iglesia y Ciudad de Michoacán no perdieran sus derechos y mercedes, especialmente si se consideraba el derecho de antigüedad que la ciudad originaria detentaba.

La patente de 28 de septiembre de 1534, mediante la cual, el Rey Carlos dio la merced a Michoacán:

5. Súplica Vasco de Quiroga al Consejo, $1^{\circ}$ de septiembre de 1552, en Vasco de Quiroga contra los Vecinos de Guayangareo, Justicia 173, N.1 R2, R12, México, 1567, AGI. foja 5. Al texto original se le agregan signos de puntuación, para mayor comprensión y por requisitos de publicación.

6. Súplica Vasco de Quiroga al Consejo, $1^{\circ}$ de septiembre de 1552, en Vasco de Quiroga contra los Vecinos de Guayangareo, Justicia 173, N. 1 R2, R12, México, 1567, AGI. foja 6. 
Don Carlos e doña Juana [...], por cuanto somos informados que la provincia de Michoacán, que es en la Nueva España de las nuestras indias del mar océano, es tierra muy fértil e abundosa de mantenimiento y otras cosas, y que no tiene otra falta sino de policía e juntarse los naturales de ella e pueblos donde la puedan tener, porque dicen que andan muy derramados por los campos sin tener conversación alguna unos con otros; ahora habemos mandado que los dichos indios que viven de fuera de poblado, se junten en un pueblo; porque a causa de así estar apartados, no pueden se bien ilustrados en las cosa de nuestra santa fe católica de que Dios nuestro señor es deservido. Y por la voluntad que tenemos que el ficho pueblo re ennoblezca e otros poblados, rece, animen a ir [...], es nuestra merced e mandamos que ahora y de aquí adelante, se llame e intitule ciudad de Michoacán, e que goce de las preeminencias prorrogativas e inmunidades que puede e debe gozar por ser ciudad, y encargamos al ilustrísimo príncipe don Felipe, nuestro muy caro e muy amado hijo e nieto e [...], a los infantes duques marqueses [...], maestres de las ordenes [...], alcalde de los castillos e casas fuertes, e llamas e a los del nuestro consejo presidente e oidores, de las nuestras audiencias, alcaldes, alguaciles de la nuestra casa e [...] Chancillerías, e a todos los corregidores e gobernadores, alcaldes, alguaciles [...], ministros, prebostes, veinte e cuatros caballeros e santeros oficiales y hombres buenos de todas las ciudades villa, e lugares de los nuestros reinos e señoríos, e de las nuestras indias islas o tierra firme del mar océano; que guarden y hagan guardar en lo con tratado en esta nuestra casa e consejo, el tenor y forma de ella no vayan ni pasen, ni asientan ir ni pasar por alguna manera, so pena de la nuestra e de diez mil maravedís para la nuestra cámara. Dada en Valencia a veinte e ocho días del mes de septiembre de mil e quinientos e treinta y cuatro años.

Yo el rey?

Aunado a la patente, en 1538, el Rey enviaría carta al obispo, concediéndole diversas facultades para administrar y mandar la Iglesia de la región, entre la que se incluirían mandatos al virrey para dotar de alguaciles, médicos y permitir el asentamiento tanto de oriundos de la Península Ibérica, como de naturales.

\section{EL CONFLICTO JURÍDICO COMIENZA}

En abril de 1543, don Vasco de Quiroga presentó reclamo ante la Audiencia de México, en razón de las acciones de los vecinos de Guayangareo en el pueblo de Tarinbaro, que por aquel entonces estaba encomendado a los «herederos de Valderrama». La queja radicaba precisamente en la fundación de otra «ciudad de Michoacán» en perjuicio de la primitiva, en contra de lo establecido por la Corona y del parecer del titular de la Mitra, por lo que en el mismo documento, se presentan la protesta del

7. Provisión para que los indios que viven fuera de pueblos en Michoacán se reduzcan a pueblo y se llame Ciudad de Michoacán, 28 de septiembre de 1534, en Vasco de Quiroga contra los Vecinos de Guayangareo, Justicia 173, N.1 R2, R12, México, 1567, AGI. fojas 8-9.

8. Carta de su Majestad al Obispo en que le daba facultad que pueda mandar la I Ilesia de Páscuaro, 25 de junio de 1539, en Vasco de Quiroga contra los Vecinos de Guayangareo, Justicia 173, N.1 R2, R12, México, 1567, AGI. fojas 11-f14. 
obispo al actuar de los Españoles que buscaban establecer el nuevo asentamiento, y por lógica, a los perjuicios que sus acciones acarrearía al Obispado?.

Es menester señalar, que el primer asentamiento de la Iglesia en la región, fue la casa y monasterio de San Francisco en el barrio de Zinzonza, el cual presentaba inconvenientes diversos, por lo que el obispo solicitó el cambio de la Iglesia y por tanto de la Ciudad al Barrio de Pátzcuaro ${ }^{10}$. Para ello solicitó la interrogación de testigos que debían responder a cuestionamientos que buscaban confirmar los siguientes problemas:

1. La mala ubicación del monasterio, así como las barrancas, los cerros «y arcado casi todo de una laguna de agua y mala conversación donde corre e reina un aire sobre el dicho sitio y valle donde está la dicha iglesia» ${ }^{11}$ que le caracterizaban.

2. La dificultad que el asentamiento presentaba para que pobladores de los barrios de las zonas bajas asistieran a la Iglesia, tanto por lo escarpado como por la hidrografía cercana, que además provocaba la ausencia de agua a la iglesia, y que los habitantes tuvieran que cavar pozos muy profundos y de mala calidad que atentaban contra la salud.

3. La mala calidad de la primera edificación (adobe y paja vieja y en condiciones paupérrimas).

4. Que dicho monasterio, por sus mismas condiciones fue abandonado.

5. Las superiores condiciones de Pátzcuaro, además de que era antes de la llegada de Cortés la cabecera de la región y a la que se consideraba la mejor zona, por su buena calidad de agua, su saludable aire, fértil tierra y lago para la pesca, siendo además parte de la Diócesis del Obispado de Michoacán.

Los testigos que respondieron al interrogatorio fueron vecinos de los lugares en cuestión, quienes confirmaron lo planteado por el obispo ${ }^{12}$. Se debe señalar que para los testigos que fueran de origen indígena, se dispusieron intérpretes que pudieran traducir tanto los cuestionamientos, como las respuestas de los entrevistados ${ }^{13}$.

9. Reclamo de Vasco de Quiroga, 8 de abril de 1543, en Vasco de Quiroga contra los Vecinos de Guayangareo, Justicia 173, N.1 R2, R12, México, 1567, AGI. fojas 18-19.

10. Información hecha a pedimento del obispo para que conste del mal asiento y disposición del lugar donde estaba la Iglesia.

11. Interrogatorio presentado por Arias Girón, procurador de Vasco de Quiroga, 9 de septiembre de 1548, en Vasco de Quiroga contra los Vecinos de Guayangareo, Justicia 173, N.1 R2, R12, México, 1567, AGI. fojas 20-21.

12. Los testigos fueron Diego Calero, Suero Asturano, Pedro Moreno, Francisco Castilleja, Juan Borallo, Domingo de Medina, Juan, quien era indígena cacique de la zona, Diego Dávalos. Interrogatorio presentado por Arias Girón, procurador de Vasco de Quiroga, 9 de septiembre de 1548, en Vasco de Quiroga contra los Vecinos de Guayangareo, Justicia 173, N.1 R2, R12, México, 1567, AGI. fojas 20-47.

13. Borah, 1985, p. 68. 
A estos testimonios, Vasco de Quiroga consideró adecuado adicionar las «Cartas y probanzas de los religiosos que estaban administrando los santos sacramentos a los españoles que dejaron ciudad y parroquia y se pusieron en Guayangareo hasta que se vuelva», dentro de las cuales destaca la misiva fray Pedro de Almonacer, quien se encontraba administrando los sacramentos en el nuevo asentamiento, y quien muestra constantes quejas respecto a que su lugar es regresar a Pátzcuaro y no estar en Guayangareo, donde una población de Castellanos es notoriamente baja para necesitar dos personas que se encarguen de sus almas y sacramentos, y que solo se encuentra ahí por su obediencia al obispo de Michoacán ${ }^{14}$.

En estas cartas se hacen incluso relaciones de las personas que se confesaban y comulgaban con ellos durante el tiempo de cuaresma, siendo apenas un poco más de cincuenta, de aproximadamente cien europeos que habitaban el lugar ${ }^{15}$.

Una de las cartas es muy llamativa, es del Bachiller Juan García de fecha 2 de enero de 1549, y en la que relata al obispo de Michoacán que el hospital de Guayangareo va muy bien, e incluso se ha ampliado, pero que lo que ya parece una labor eterna, es el caño que por parte de indígenas, se está realizando para los hispanos del lugar, además de que los naturales (casi doscientos) se encuentran sobreexplotados en dicha obra, especialmente por el Alcalde Mayor Jorge Cero, quien está tomando toda la cal y la piedra, para la construcción de esa y otras obras, en perjuicio de la Iglesia del lugar.

Aunado a estos problemas, los frailes de Zinzoza, Teremando, Guayangareo y Cacapo, obligan a los indígenas a asistir a misa, a lugares alejados, cuando en realidad se podrían repartir, por cercanía y número muy bien a todos los nativos. Otro problema que el fraile reporta al obispo, consiste en un tipo de disputa por las confesiones, entre clérigos y frailes, en el que los primeros aseveran a los indígenas, que las confesiones realizadas con los segundos, no son igualmente válidas, por lo que el fraile suplica a Vasco de Quiroga que ayude a resolver dicha situación' ${ }^{16}$

En otro documento, pero de fecha 17 de marzo de 1549, Vasco de Quiroga, recibió del bachiller Juan García noticia de que el provincial franciscano se había admirado de la cantidad de naturales que asistían a misa en Michoacán, siendo nada más que fray Toribio de Benavente el provincial al que hacía referencia:

El provincial es un fray Francisco, que los indios Ilaman Motolinia; holgó se tanto de y la cristiandad y buena orden de ella, que halló en el obispo de vuestra señoría, que iba dando gracias a nuestro señor diciendo que en toda la Nueva

14. Cartas y probanzas de los religiosos que estaban administrando los santos sacramentos a los españoles que dejaron ciudad y parroquia y se pusieron en Guayangareo hasta que se vuelva, s/f, en Vasco de Quiroga contra los Vecinos de Guayangareo, Justicia 173, N.1 R2, R12, México, 1567, AGI. foja 49.

15. Cartas y probanzas de los religiosos que estaban administrando los santos sacramentos a los españoles que dejaron ciudad y parroquia y se pusieron en Guayangareo hasta que se vuelva, s/f, en Vasco de Quiroga contra los Vecinos de Guayangareo, Justicia 173, N.1 R2, R12, México, 1567, AGI. fojas 50-60. 16. Cartas y probanzas de los religiosos que estaban administrando los santos sacramentos a los españoles que dejaron ciudad y parroquia y se pusieron en Guayangareo hasta que se vuelva, s/f, en Vasco de Quiroga contra los Vecinos de Guayangareo, Justicia 173, N. 1 R2, R12, México, 1567, AGI. fojas 60-69. 
España, entre los naturales, no había la mitad de la cristiandad, ni de tres partes una, como en la provincia de Michoacán, y llevaba gran voluntad de lo comunicar con el señor visorrey ${ }^{17}$.

En esta misiva, el bachiller informaba también al obispo de Michoacán, que los indios de Guayangareo pasaban penurias diversas, llegando a un número de seiscientos los explotados en la nueva ciudad. A tal grado llegaron los abusos, que el mismo Juan García. Se había visto en la obligación de redactar en propia mano las quejas de las principales autoridades para dirigirlas al virrey Antonio de Mendoza. Las quejas, fueron reproducidas y duplicadas en un documento de fecha 10 de marzo de 1549 que fue enviada al obispo de Michoacán, y en las cuales afirman diversos tipos de despojos, maltratos y abusos; los indígenas principales fueron don Alonso, don Marcos, don Alonso Vitzi y don Ramiro ${ }^{18}$.

El 22 de mayo de 1545, el Rey Carlos V emitió una provisión para que el obispo De Quiroga mandara sacerdotes a Guayangareo, la cual le fue notificada el 30 de junio de 1545, y que a la letra dice:

a vos el reverendo y padre don Vasco de Quiroga, obispo de la ciudad de Michoacán, e del nuestro consejo; salud e gracias. Sepades que por parte del cabildo justicia e regimiento de la dicha ciudad, nos ha sido fecha relación que no embargante en los diezmeros de ese obispado, les dan los diezmos de los vecinos de esa ciudad, e os acuden con ellos como a pelado no ponerse en la dicha ciudad curas e clérigos que les administren los santos sacramentos e celebren los divinos oficios, a cuya causa compadecido e padezcan gran riesgo e peligro sus ánimos e conciencias; e nos fue suplicado e pedido por merced diezmos, le pusiesen en la iglesia clérigos que los administrasen en los santos sacramentos, o que, sobre ello, proveyésemos como la nuestra merced fuese; lo cual visto por el presidente e oidores de la nuestra Audiencia e Chancillería Real que reside en la ciudad de México de la Nueva España, e porque no es justo que los vecinos de la dicha ciudad carezcan de suso dicho, fue acordado que debíamos mandar dar esta cura carta en la dicha razón, e nos tuvimos por bien por la cual vos rogamos y encargamos en la iglesia de la dicha ciudad de Michoacán, a los vecinos de ella, clérigos que los administren los santos sacramentos e celebre los divinos oficios, e proveáis las demás cosas necesarias al culto divino; con apercibimiento que no lo haciendo, se preverá lo que convenga al servicio de Dios nuestro señor e nuestro ${ }^{19}$.

A esto, Vasco de Quiroga, respondería el 3 de julio del mismo año (1545) mediante un documento en el que argumentó:

- Que dada su calidad de primer prelado consagrado no podía librarse tal provisión en su contra, dado que él era en efecto el árbitro y moderador de su

17. Carta de Juan García a Vasco de Quiroga, en Vasco de Quiroga contra los Vecinos de Guayangareo, Justicia 173, N.1 R2, R12, México, 1567, AGI. foja 72.

18. De los Principales de Michoacán al Obispo Vasco de Quiroga, en Vasco de Quiroga contra los Vecinos de Guayangareo, Justicia 173, N.1 R2, R12, México, 1567, AGI. fojas 82-89.

19. Testimonio de la notificación de la Provisión de México para que pusiese curas en Michoacán, 30 de junio de 1545, en Vasco de Quiroga contra los Vecinos de Guayangareo, Justicia 173, N.1 R2, R12, México, 1567, AGI. fojas 93-94. 
Obispado, el cual en efecto sufría una gran pobreza, por lo cual apenas podía sustentar las propias necesidades.

- Que el lugar donde residía su Obispado, era en realidad la verdadera y original Michoacán, en donde brindaba todos los servicios necesarios a los habitantes20, y se niega a aceptar que Guayangareo sea nombrada igual que la sede del obispado:

nadie es obligado a dar a otro lo que a menester para si, aunque sea la madre al hijo que pario; ante dicho obispo y su iglesia, a la nueva que así se quiere hacer en Guayangareo en su perjuicio, lo que no tienen y han tanto menester por así y para sus necesidades y habitables, que si se les quitase algo, no se podrían sustentar conforme a la erección, y esto solo bastaba para dejar y ha de ser más molestado contra justicia e razón, pues es cosa tan notoria en hecho y en derecho ${ }^{21}$.

- Que los residentes de Guayangareo acudieron a ese lugar sin permiso ni consejo de su obispo, sino sólo del virrey Antonio de Mendoza, y que la orden de dotar de más sacerdotes a ese lugar no sería posible de ejecutar con la lastimosa condición económica del Obispado, y aún pese a ello, Vasco de Quiroga afirma que mantiene a los vecinos y moradores de la población bien proveídos acorde a sus posibilidades ${ }^{22}$, y establece:

No es el dicho obispo obligado a cumplir necesidades ajenas de otras algunas y cualesquier iglesias nuevas, que sean o ser puedan, no siendo bastante para las de su propia iglesia como es notorio por grandes y extremas que sean la ajenas $y$, en esto, se renueve a que esta materias y menos que otras las de la iglesia del dicho sitio de Guayangareo, que los dichos pobladores del voluntariamente, quieren en ella hacer por ser contra el voto, y parezca del dicho obispo, y habiendo así según y como dicho es desamparándola dicha iglesia y verdadera ciudad de Michoacán, donde eran vecinos y moradores y parroquianos, lo cual todo ellos, de industria y cautelosamente [...] y incumbieron en la dicha su petición inserta en la dicha provisión ${ }^{23}$.

- En el anterior sentido, también afirma que el lugar en donde se asentaron, el obispo lo consideró siempre un lugar yermo, ventoso, solitario y poco apto para un asentamiento, además de la distancia de ocho leguas que la separa

20. Testimonio de la notificación de la Provisión de México para que pusiese curas en Michoacán, 30 de junio de 1545, en Vasco de Quiroga contra los Vecinos de Guayangareo, Justicia 173, N.1 R2, R12, México, 1567, AGI. fojas 97-99.

21. Testimonio de la notificación de la Provisión de México para que pusiese curas en Michoacán, 30 de junio de 1545, en Vasco de Quiroga contra los Vecinos de Guayangareo, Justicia 173, N.1 R2, R12, México, 1567, AGI. foja 107.

22. Testimonio de la notificación de la Provisión de México para que pusiese curas en Michoacán, 30 de junio de 1545, en Vasco de Quiroga contra los Vecinos de Guayangareo, Justicia 173, N.1 R2, R12, México, 1567, AGI. fojas 97-99.

23. Testimonio de la notificación de la Provisión de México para que pusiese curas en Michoacán, 30 de junio de 1545, en Vasco de Quiroga contra los Vecinos de Guayangareo, Justicia 173, N.1 R2, R12, México, 1567, AGI. foja 99. 
del Obispado, y la ausencia de indios con los cuales comerciar, por lo que aconsejó en contra del asentamiento, el cual de todas formas se llevó a cabo por varios hispanos, que además, podían solicitar el regreso a Michoacán, en donde podrían gozar de mayores beneficios ${ }^{24}$.

Y lo otro por la administración de los santos sacramentos y culto divino, que los dichos pobladores piden para el dicho de Guayangareo, ellos lo tienen en esta iglesia catedral de Michoacán, donde eran parroquianos, y no se pudieron así desmembrar voluntariamente, y a su albedrio y su perjuicio, son causa legítima contra el parecer y reclamación sobre ello en forma hecha por los dichos obispo iglesia y ciudad, donde si necesidad tienen de sacramentos y culto divino se podrán volver ${ }^{25}$.

Lo otro, porque de la dicha iglesia catedral su majestad es patrón, y para la erigir en esta ciudad de indios, que era la cabeza de toda la provincia, a quien toda ella y la comarca de ella obedecía y reconocía, por ser la cosa mejor y más principal que en ella había la crió y erigió en ciudad, y le dio por su patente privilegios y prerrogativas y preeminencias de ciudad, y que se llamen la ciudad de Michoacán, porque así cumplía a su servicio real, porque había de ser en ella casilla y audiencia episcopal y iglesia catedral; y también, para hacer bien y merced a los naturales de ella, y después su santidad a suplicación de su majestad por sus bulas patentes, así mismo la erigió en ciudad de Michoacán, y la dicha iglesia catedral en ella y por prelado y obispo de ella al dicho obispo de Michoacán, según que por las bulas de la erección por las cartas y patentes de su majestad consta y parece, de que protestaba hacer dotación, por el cual erección se manda que se acuda al dicho obispo con todos los diezmos de su obispado, y ahora también su majestad le ha mandado enviar, y le ha enviado ordenada, la erección del repartimiento de los del diezmos, y a mandar que así la otorgue y la envié otorgada y firmada la dicha erección ${ }^{26}$

- Afirma también que a pesar de que los pobladores de Guayangareo pagasen diezmos, el propósito de estos no son el pago de sacramentos, sino se pastura y hierba para el ganado, y aún si se destinaran los diezmos de manera exclusiva para dicho propósito, no dejaría de ser excesivamente pesado para un Obispado con tantas necesidades ${ }^{27}$.

24. Testimonio de la notificación de la Provisión de México para que pusiese curas en Michoacán, 30 de junio de 1545, en Vasco de Quiroga contra los Vecinos de Guayangareo, Justicia 173, N.1 R2, R12, México, 1567, AGI. fojas 99-104.

25. Testimonio de la notificación de la Provisión de México para que pusiese curas en Michoacán, 30 de junio de 1545, en Vasco de Quiroga contra los Vecinos de Guayangareo, Justicia 173, N.1 R2, R12, México, 1567, AGI. foja 105.

26. Testimonio de la notificación de la Provisión de México para que pusiese curas en Michoacán, 30 de junio de 1545, en Vasco de Quiroga contra los Vecinos de Guayangareo, Justicia 173, N.1 R2, R12, México, 1567, AGI. foja 111.

27. Testimonio de la notificación de la Provisión de México para que pusiese curas en Michoacán, 30 de junio de 1545, en Vasco de Quiroga contra los Vecinos de Guayangareo, Justicia 173, N.1 R2, R12, México, 1567, AGI. foja 108. 
- Así también, el obispo hace referencia a los intereses que varios de los habitantes de Guayangareo tienen de agradar al virrey De Mendoza, principal promotor de la nueva población.

El requerimiento de Guayangareo, relacionado con la dotación de curas y clérigos, databa de $1543^{28}$, el cual iba firmado por Andrés de Vargas, Gregorio de Aviña, Juan Pantoja, Pedro Moreno, Diego Martín Infante y Alonso de Toledo, quienes conformaban el Cabildo de la Nueva Michoacán, que tuvo indudablemente respuesta muy similar por parte de don Vasco de Quiroga, quien afirmó en todo momento la pobreza del Obispado y su negación a desmembrar el Obispado original ${ }^{29}$, «estando la dicha su iglesia catedral tan pobre y tan necesitada de todo lo que piden por más necesidad que la iglesia nueva tenga se prefiere la necesidad de la vieja porque de otra manera sería verdaderamente descubrir un altar por cubrir otro lo que no se puede ni debe hacer de más de esto el dicho obispo no a mandado hacer la dicha iglesia nueva y los que la hacen y fundan serían obligados a la dotar competentemente de rentas o heredades» ${ }^{30}$; la petición fue al tenor siguiente:

El cabildo justicia, y regidores, y vecinos de la nueva población de la ciudad de Michoacán, vuestros diocesanos y sus [...], encomendamos en vuestra señoría reverendísima, y le hacemos saber como sabe y le es notorio a vuestra señoría, que por los muchos impedimentos e inconvenientes que a los indios naturales de esa ciudad se les seguían en sus labranzas y en la libertad de sus personas e haciendas, con acuerdo y parecer del señor visorrey d esta Nueva España, presidente y oidores de su majestad, y comparecer y consulta que se hizo a su majestad, nos pasamos a poblar a esta nueva población a do[nde] estamos poblados, todo a efecto de sustentar esta provincia con harto gasto trabajo de nuestras personas y hacienda, porque en esa ciudad no las podíamos sustentar y tener perjuicio de los naturales y de sus labranzas, y pues a vuestra señoría le costa todo esto, y que todos los vecinos de esta provincia estamos aquí poblados con nuestras cosas y mujeres, y por otras muchas peticiones le hemos pedido y suplicado que, pues le pagamos los diezmos de nuestras crianzas y labranzas, fuese servido de nos proveer y pues tenemos iglesia hecha y su majestad, nos ha hecho merced de nos la mandar hacer, de proveernos de curas y capellanes y ornamentos con que se nos administren los santos sacramentos y divinos oficios, pues a ello es obligado y no lo ha proveído hasta ahora, de lo cual recibimos muy gran daño y perjuicio en nuestras conciencias y personas, lo cual todo pertenece remediar y proveer a vuestra señoría como a nuestro prelado y obispo de esta provincia etc.

28. Petición y requerimiento de la Nueva Ciudad de Michoacán al Obispo que les de curas y clérigos, 7 de junio de 1543, en Vasco de Quiroga contra los Vecinos de Guayangareo, Justicia 173, N.1 R2, R12, México, 1567, AGI. foja 130.

29. Notificación de la Petición y requerimiento de la Nueva Ciudad de Michoacán al Obispo que les de curas y clérigos, 7 de junio de 1543, en Vasco de Quiroga contra los Vecinos de Guayangareo, Justicia 173, N.1 R2, R12, México, 1567, AGI. fojas 132-134. El orden de las fojas se altera para una mejor comprensión del lector.

30. Notificación de la Petición y requerimiento de la Nueva Ciudad de Michoacán al Obispo que les de curas y clérigos, 7 de junio de 1543, en Vasco de Quiroga contra los Vecinos de Guayangareo, Justicia 173, N.1 R2, R12, México, 1567, AGI. fojas 136-137. 
A vuestra señoría pedimos y suplicamos y encargamos la conciencia que lo provea con brevedad, y si necesario es, con el acatamiento que debemos perentoriamente, se lo pedimos y requerimos que lo mande proveer o responder lo que determina hacer, y mandamos lo dar todo por testimonio para que con ello [...] a su majestad o a los señores presidente e oidores de su real audiencia para que lo provean y remedien ${ }^{31}$.

Cabe señalar que en la respuesta del obispo de Michoacán, un punto argumentativo reiterado, es la necedad de los habitantes de Guayangareo de retirarse a vivir a un lugar lejano y poco conveniente, incluso en contra del consejo del Prelado, y por agradar al virrey De Mendoza, por lo que agrega que éste último es quien debe entonces proveerles:

cuando justa causa hubiese para mudarse al sitio donde están, de que hace como dicho tiene no le consta tienen al señor visorrey, que como provee que de los residos de los corregimientos y cerca de su majestad se les hagan las cosas, proveerá de que se sustente el clérigo y de que se compren ornamentos ${ }^{32}$

Así también, en el Instrumento de Suplicación de 10 de septiembre de 1552, el obispo De Quiroga, reiteraba frente al Consejo de Indias los puntos principales de su defensa del original obispado:

1. La posibilidad de los vecinos de Guayangareo de retornar al Obispado de Michoacán en donde nada les falta.

2. La petición de que no forcen a los indígenas a trabajar en las obras públicas de la nueva ciudad, tal como había ordenado el virrey.

3. La siempre disposición de religiosos para atenderles, pero acorde a las posibilidades del Obispado.

4. La negación a que usurpen el nombre de Michoacán, que pertenece al Obispado original.

\section{EL FINAL DE LA DISPUTA}

El Consejo determina que Michoacán es la sede de don Vasco y que el Valle de Guayangareo, debe recibir las cédulas o provisiones necesarias para tener un nombre propio y adecuado ${ }^{33}$.

31. Notificación de la Petición y requerimiento de la Nueva Ciudad de Michoacán al Obispo que les de curas y clérigos, 7 de junio de 1543, en Vasco de Quiroga contra los Vecinos de Guayangareo, Justicia 173, N.1 R2, R12, México, 1567, AGI. fojas 130-131.

32. Notificación de la Petición y requerimiento de la Nueva Ciudad de Michoacán al Obispo que les de curas y clérigos, 7 de junio de 1543, en Vasco de Quiroga contra los Vecinos de Guayangareo, Justicia 173, N.1 R2, R12, México, 1567, AGI. foja 139.

33. Suplicación del Obispo De Quiroga al Consejo de 10 de septiembre de 1552, en Vasco de Quiroga contra los Vecinos de Guayangareo, Justicia 173, N.1 R2, R12, México, 1567, AGI. fojas 144-147 y Emplazamiento del Consejo, foja 147. 
Pese lo anterior, el conflicto todavía duraría, ya que con fecha 30 de abril de 1567 (dos años después de la muerte del obispo de Michoacán), se presentaría frente al Consejo de Indias, un poder por parte del Cabildo de Guayangareo, a favor de Alonso De la Veracruz, a fin de que éste pudiera ejercer como procurador en la disputa por el nombre de la ciudad, así como la oposición del Obispado a que dicha población fuera habitada ${ }^{34}$. Dentro de los hechos reclamados se encontraban:

1. Que el Valle de Guayangareo era habitable.

2. Que el obispo no tenía ni personalidad ni autoridad para prohibir la fundación de la ciudad.

3. Que el Obispado original, era el que carecía de calidad para que los españoles vivieran ahí, dada la presencia de los indígenas y la preocupación del obispo respecto a ellos ${ }^{35}$.

En defensa de la Ciudad, el también procurador de la misma, Alonso de Herrera, presentó también traslado de la Comisión del virrey Antonio de Mendoza con el que se fundaba la ciudad, bajo el nombre, cabe remarcar de Michoacán, al siguiente tenor:

Yo don Antonio de Mendoza, visorrey gobernador por su majestad en esta Nueva España y presidente de su Audiencia e Chancillería Real que en ella reside, e por cuanto siendo informado su majestad que la ciudad de Michoacán se había puesto y asentado en parte y lugar no conveniente, y que había necesidad de se mudar a otra parte; me envía mandar que informado de lo susodicho hiciese asentar la dicha ciudad en parte y lugar conveniente y necesaria, para la perpetuación de ella en cumplimiento de los cual; estando en la dicha ciudad de Michoacán, me informe de los susodicho e que convenía mudarse y me costa que no había otra mejor parte donde se pudiese asentar y sin menos perjuicio e mas convincente que es; todo dicen Guayangareo por haber en la parte susodicha fuentes de agua, e cerca las demás cosa necesarias para la población e perpetuación de la dicha ciudad e proveimiento de los vecinos de ella e tierras, por poder hacer sus heredares e tener sus granjerías sin perjuicio de los indios.

Por ende, por la presente, señalo el dicho sitio de Guayangareo para que en el se asiente la dicha ciudad de Michoacán, e porque para la traca de ella e repartimiento de solares que se han de dar a los vecinos de la dicha ciudad, para hacer sus casas y heredades e otros repartimientos, convienen nombrar personas que entiendan en los susodicho; con fundo de vos Juan de Alvarado e Juan de Villaseñor e Luis de León Romano que sois tales personas que entenderéis en lo susodicho bien e fielmente mirando el servicio de su majestad, e bien de la dicha ciudad por la presente, vos mando que en el dicho sitio e lugar de suso nombrado, hagáis e se asiente la dicha ciudad de Michoacán, y entendáis en la traca y repartimiento de ella por la mejor forma y orden que os pareciere e vieredes, que más convenga

34. Poder de Fray Alonso De la Veracruz, 9 de enero de 1566, presentado en Consejo el 30 de abril de 1567, en Vasco de Quiroga contra los Vecinos de Guayangareo, Justicia 173, N.1 R2, R12, México, 1567, AGI. fojas 149-155.

35. El Pueblo de Guayangareo con el Obispo de Michoacán sobre que el dicho Obispo impide la población de dicho Pueblo, 4 de Junio de 1567. 
para la perpetuación ennoblecimiento de la dicha ciudad, señalando sitios e partes donde se haga la iglesia mayor e casa episcopal, e monasterios, e casa de cabildo, e cárcel pública, e las demás que convenga para el ornato y ennoblecimiento de la dicha ciudad; solares donde puedan hacer hagan sus casas y les den tierras donde hagan sus heredades y huertas moderadas e convenientes, e sin perjuicio, e así mismo entendáis en que se hagan los caminos e puentes necesarios para los montes e canteras y otras partes convenientes los cuales hagan y abran los indios de la comarca, y en el repartimiento de las dichas heredades e solares, tengáis respeto e consideración, así calidades de cada uno e a los demás que a ella se fueren a vivir e avecindar, les deis el dicho repartimiento de solares para casas e heredades como a los demás e la dicha traca e repartimiento que hicieredes, firmada de vuestro nombre, la invadan ante mi para que yo la vea, para lo cual dicho es, os doy poder cumplido con sus incidencias e dependencias, anexidades e conexidades, según que en tal caso se requiere, y os mando que entendáis en lo susodicho con todo cuidado e diligencia según que de vosotros se confía.

Fecho en México a veinte y tres días del mes de abril de mil e quinientos e cuarenta e un años.

Don Antonio de Mendoza ser por mandado de su señoría ${ }^{36}$

Igualmente, el procurador presentó una Provisión del Rey para que los alcaldes ordinarios conocieran en primera instancia de las vejaciones que acorde a informes recibidos, sufrían los indígenas a manos de europeos, así como un mandato del virrey De Mendoza para aumentar el comercio en la zona, mediante la imposición de que los bastimentos fueran vendidos en el nuevo asentamiento, así como otras provisiones $^{37}$.

Todo lo anterior, sería confirmado por el Visitador Lorenzo Lebrón de Quiñones, a quien se le presentaría una petición de parte de los vecinos de la nueva población, exigiendo el cumplimiento tanto del aumento del comercio (lo que se convertiría en el Tianguis de Guayangareo) así como poder alquilar indígenas para labranza y otros trabajos. Los pueblos que solicitaban, fueran compelidos a colaborar en estas peticiones eran Pátzcuaro, Tiripitio, Capula, Comanja, Carandangacho, Cacapo, Guango, Cuiseo, Terinbro, Cincipecuaro, Ucareo, Chiquimitio, Taimeo, Yndapapeo, Matalcingo, Necotlán, entre otros ${ }^{38}$. De los que afirmaban, podían existir más de treinta mil indios para «carga» ${ }^{39}$, por lo que solicitaban que se ordenara a los enco-

36. Comisión del Virrey Antonio de Mendoza, 23 de abril de 1541, presentado en Consejo el 4 de junio de 1567, en Vasco de Quiroga contra los Vecinos de Guayangareo, Justicia 173, N.1 R2, R12, México, 1567, AGI. fojas 157-158.

37. Traslados de Alonso de Herrera ante el Consejo de Indias, en Vasco de Quiroga contra los Vecinos de Guayangareo, Justicia 173, N.1 R2, R12, México, 1567, AGI. fojas 161-178.

38. Pedimento de la Ciudad de Michoacán al muy magnífico licenciado Lebrón de Quiñones de 18 de diciembre de 1554, en Vasco de Quiroga contra los Vecinos de Guayangareo, Justicia 173, N.1 R2, R12, México, 1567, AGI. fojas 195-198.

39. Quiroga menciona en la Información en Derecho de manera escueta una provisión que regula la figura de los tamemes. La primera vez que se regula esta figura por parte de las autoridades hispanas es en las Ordenanzas dadas por el Emperador Carlos V, dirigidas a la Audiencia, a los obispos, y a los 
menderos y corregidores que los mandaran a residir en la ciudad. El Oidor Lebrón, ordenó que en todo lo indicado por el virrey, se proveyera acorde ${ }^{40}$.

\section{CONCLUSIÓN}

La lectura del expediente en el que consta el pleito de Vasco de Quiroga contra los vecinos de Guayangareo, lleva a dos importantes afirmaciones: la primera, el uso y abuso que los europeos tenían y deseaban ejercer aún más presión sobre los naturales; en segundo lugar, la notoria discriminación que principalmente los peninsulares tenían en contra de los indígenas.

Don Vasco de Quiroga intentó, mediante el pleito aquí expuesto, así como mediante la fundación de hospitales en la Nueva España; el combatir las tendencias egoístas de los europeos, que derivaban en la explotación de los naturales, que los rebajaban a prácticamente una condición de esclavos.

La intención del obispo michoacano, no era romper con su feligresía, sino alentar en ellos un verdadero sentimiento de comunidad, que abarcara tanto a indígenas como a los peninsulares. Su labor, tardaría mucho tiempo en rendir frutos, ya que, pese a la sentencia que le resultó favorable, se fundó una nueva ciudad con identidad puramente europea, que hoy en día, de manera por demás llamativa, es la capital de todo el Estado de Michoacán: la ciudad de Morelia.

\section{FUENTES DE INFORMACIÓN}

Archivo General de Indias (AGI)

Justicia 173, N.1 R2, R12, México, Vasco de Quiroga contra los Vecinos de Guayangareo, 1567 .

\section{BIBLIOGRAFÍA}

Borah, Woodrow, El Juzgado General de Indios en la Nueva España, trad. Utrilla Juan José, México, FCE, 1985.

Callens, Paul L., Tata Vasco. Un gran reformador del siglo XVI, Figuras y Episodios de la Historia de México, México, Jus, 1959.

Fernández Rodríguez, Pedro, Los dominicos en el contexto de la primera evangelización de México, 1526-1550, Salamanca, San Esteban, 1994.

Superiores de los monasterios de Santo Domingo y San Francisco en la Nueva España de 4 de diciembre de 1528. Ver Fernández Rodriguez, 1994, p. 117.

40. Pedimento de la Ciudad de Michoacán al muy magnífico licenciado Lebrón de Quiñones de 18 de diciembre de 1554, en Vasco de Quiroga contra los Vecinos de Guayangareo, Justicia 173, N.1 R2, R12, México, 1567, AGI. Fojas 198-202. 